\title{
HEAT TRANSFER ENHANCEMENT AND FRICTION IN DOUBLE PIPE HEAT EXCHANGER WITH VARIOUS NUMBER OF LONGITUDINAL GROOVES
}

\author{
Putu Wijaya Sunu ${ }^{a *}$, Daud Simon Anakottapary ${ }^{a}$, I Made Suarta ${ }^{a}$, \\ I Dewa Made Cipta Santosa ${ }^{a}$, Ketut Suarsana $^{b}$ \\ ${ }^{a}$ Bali State Polytechnic, Mechanical Engineering Department, Kampus Bukit Jimbaran, Jalan Uluwatu 45 Kuta \\ Selatan, 80361 Badung, Bali, Indonesia \\ ${ }^{b}$ Udayana University, Faculty of Engineering, Mechanical Engineering Department, Kampus Sudirman, Jalan \\ P.B. Sudirman, 80232 Denpasar, Bali, Indonesia \\ * corresponding author: wijayasunu@pnb.ac.id
}

\begin{abstract}
It has been found out that heat exchangers with longitudinal grooves produce better heat transfer than those without longitudinal grooves. However, up to now, there have been few investigations and applications of longitudinal grooves in relation to heat transfer associated with friction from the annulus of a heat exchanger. The present investigation examined the effects of longitudinal grooves in a double pipe heat exchanger on the characteristics of heat transfer and friction. Longitudinal rectangular grooves were carved into the outer side of a tube at a specified depth (t) and width (l). The effect of the number of longitudinal grooves, Reynolds number (Re), on the thermal and hydraulic performance was evaluated based on the heat exchanger experimental data. A total of four pipes were used: one pipe with 2 grooves, one pipe with 4 grooves, one pipe with 6 grooves and one pipe with 8 grooves. Water, hot and cold, was used as the working fluid. The test was performed with the cold water as the working fluid, with the Reynolds number from about 33000 to 46000 in a counter-flow scheme. The result showed that the number of grooves improved the heat transfer and caused a pressure drop. The increase in heat transfer ranged from 1.05 to 1.15, and the pressure loss of the system reached almost $30 \%$ as compared with the smooth annulus, the annulus with no groove. The installation of longitudinal grooves in a heat exchanger system enhanced the process of the heat flow through the boundary but provided a compensation for the pressure loss, which was correlated with the friction and pumping power.
\end{abstract}

KEYworDS: Heat transfer, heat exchanger, longitudinal grooves, friction.

\section{INTRODUCTION}

A heat exchanger is the most significant industrial equipment widely used for handling thermal energy [1, 2]. One type of a heat exchanger that is widely used is the double pipe heat exchanger. Such a heat exchanger has a compact structure that can effectively transfer heat. A special interest has been spurred in designing and manufacturing a heat exchanger that is compact in its structure yet efficient in terms of costs, material, and energy. There are some significant performance parameters of a double pipe heat exchanger, such as the temperature of the hot and cold fluid, the flow rate of each working fluid, and pressure difference [3]. The thermal performance of a double pipe heat exchanger can be improved by a heat transfer enhancement technique. The heat transfer mechanism in a heat exchanger can potentially be improved fundamentally by generating turbulence in the fluid flow, for example, by adding a corrugated tube [4, 5], a twist tape [6, 17, a groove [8, 9], etc. This method is widely known as the passive technique, a technique that extends the surface heat transfer area through a surface modification and surface extension with minor changes in the diameter, without using any additive and energy input, yet is easy to install [10].

Grooving, with its thermo-hydraulic performance, is the most promising passive technique. Such a technique has been extensively studied in engineering applications. Over the last few decades, numerical and experimental investigations have been carried out to examine various types of an internally grooved pipe within thermal and fluid science [11-14]. The grooves potentially improve the heat transfer by extending the surface area with a slight change in the pipe diameter. Although it offers a considerable enhancement of heat transfer, the internally grooved tube usually causes an increase in friction and pressure drop [15, 16. The interaction that occurs between the grooves and the fluid flow inside the heat exchanger system is a very important mechanism. Many studies have been carried out to examine various parameters of grooves. The details of the flow structure have been shown to be able to control and improve the flow condition [17]. Using various parameters, [18] investigated a spirally corrugated tube. Moreover, the spirally-grooved tube was very feasible for an application in seawater de- 
salination and caused an enhancement of the heat transfer [19. Another shape of grooves 20] used for transversely grooved tube using molten salt as the hot fluid flowing through the inner concentric tube with the range of the Reynolds number from 300 to 60000 was found to cause a heat transfer enhancement by 1.6. 21] investigated the flow pattern and heat transfer in the transversally grooved channel for a pulsatile flow. They found that the heat transfer enhancement factor was 2.74 when the oscillatory fraction was 1.4. 22 investigated the implementation of nano-fluid and found that it greatly enhanced the heat transfer of a helically corrugated tube. [23] explored the roughened tube surface and found that 2.73 was the maximum increased value. Some researchers have examined the performance of rectangular grooves [24 28 , and discovered that the rectangular grooves influenced the thermal and hydraulic performance. 29 studied the micro-grooved surface to examine whether it could enhance flow boiling. Grooves were found to generate bubbles increasing the heat transfer coefficient by about $10 \%-15 \%$. 30] studied the effects of horizontal and vertical surface grooves on hydrodynamic performance of heated and non-heated spheres at room temperature and found that the horizontal grooves had a remarkable effect on the performance. 31] investigated the thermal behaviour of chamfer $\mathrm{V}$-grooves used as a vortex generator to affect the flow in a heat exchanger channel at Reynolds number ranging from 5300 to 23000 . The findings of the present study corroborated those of 31 that a heat exchanger with grooves performed better than that without any grooves. For an application in the renewable and clean energy field, the grooving technology should improve the thermal systems. 32] conducted a study to investigate the thermal performance of a material enriched with square, circular and trapezoidal internal grooves and discovered that the structure could increase the heat transfer rate by $27 \%$. According to these researches, the application of differently shaped grooves generally leads to an increase in the amount of heat transfer.

Although several papers have studied the heat transfer in heat exchangers using modified surfaces, the influence of a longitudinal rectangular groove pattern on the heat transfer and pressure reduction has not been comprehensively studied. The axial/longitudinal corrugated surface has been found to increase the heat transfer by $15-30 \%$ with a constant pumping power in the laminar flow 33, 34 and turbulent airflow 35 . The axial/longitudinal and radial grooves also bring benefits to the heat pipe, the drag in pipe flow, reduction of aerodynamic noise, and the pressure difference between the projectile head and the concrete wall 36 41. 42 examined a longitudinally grooved channel to enhance the diffusive transport on moderate Re and discovered the saturated flow that could intensify spanwise motions enhancing the advective transport.
There have been few investigations into heat transfer in terms of friction, especially in a longitudinally grooved heat exchanger. The grooved annulus room of a double pipe heat exchanger has received little attention, especially those using a high Reynold number (Re). However, the features of longitudinal grooves have not been clarified yet, which motivates the present investigation. Therefore, a special consideration has been given to increasing the heat transfer with a minimum pressure loss penalty by using longitudinal grooves. The novelty of the findings of the present study lies in the number of longitudinal grooves installed in the annulus used for the intensification of the heat transport at high $(\operatorname{Re}>33000)$ values of the Reynolds number. The specific objective of the study was to evaluate the effectiveness of such a technique, identifying the number of the transfer unit (NTU), the enhancement of heat transfer, and friction of heat exchangers constructed using a longitudinal rectangular groove pattern to improve the thermo-hydraulic performance of the heat exchanger.

The next section (section 2) presents the experimental procedure, describing the details of the experiment. Moreover, well-defined mathematical equations used in this study in the data reduction part are also presented. Subsequently, the results and discussion are presented from the experimental data (section 3). The last part (section 4) contains the conclusion of the present study.

\section{EXPERIMENTAL METHOD}

The outline schema of the experimental test rig is shown in Figure 1 below. It mainly consists of three major groups, namely a heat exchanger test section, hot and cold fluid loop and an instrumentation or data acquisition monitoring system. Figure 2 shows the horizontal orientation of a double pipe heat exchanger test section equipped with longitudinal grooves. To allow changes and modifications of the test section for experimental design parameters, the test rig was divided into test sections of the heat exchanger, namely the flange assembly connections of the test section and the piping loop system. Furthermore, the loop component consisted of a hot- and cold-water centrifugal pump that circulates the fluid within the loop, a full set of rotameters used to adjust the flowrate to the desired level and control it and storage tanks that contained the working fluid circulating within the loop. Meanwhile, the data acquisition device digitally recorded the temperature and pressure of the inlet and outlet of the annulus. All of the instrumentation equipment was installed at each important measurement point in the test section of the experimental apparatus. This investigation used the counter flow schema in a double pipe heat exchanger so that the hot fluid entry section came in contact with the cold fluid exit section and vice versa. To avoid a heat loss from the heat exchanger to the ambient, all loop and 


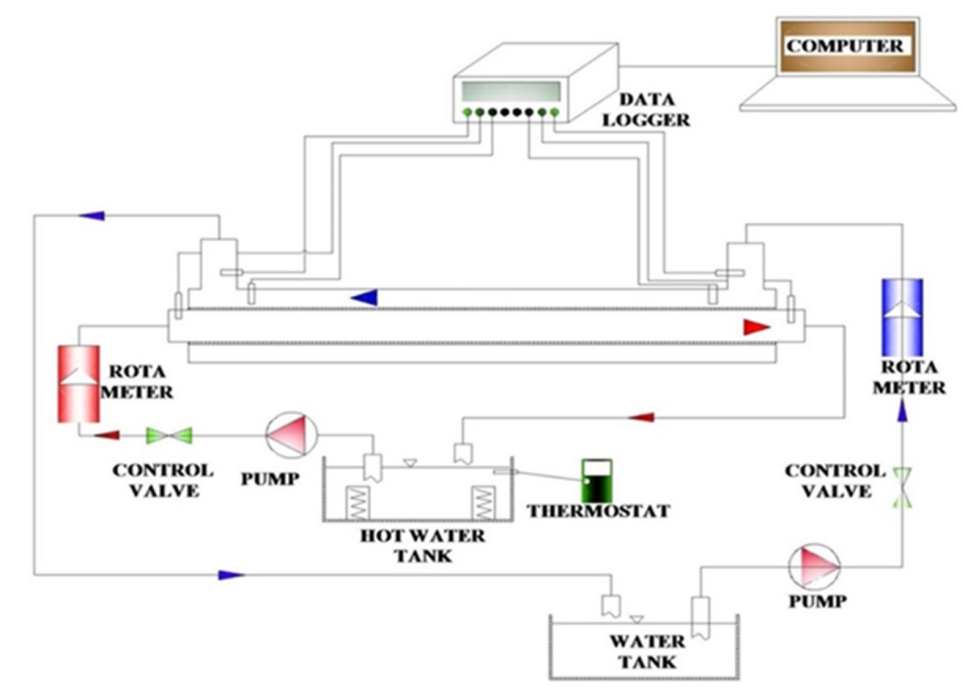

Figure 1. The outline of the experimental apparatus.

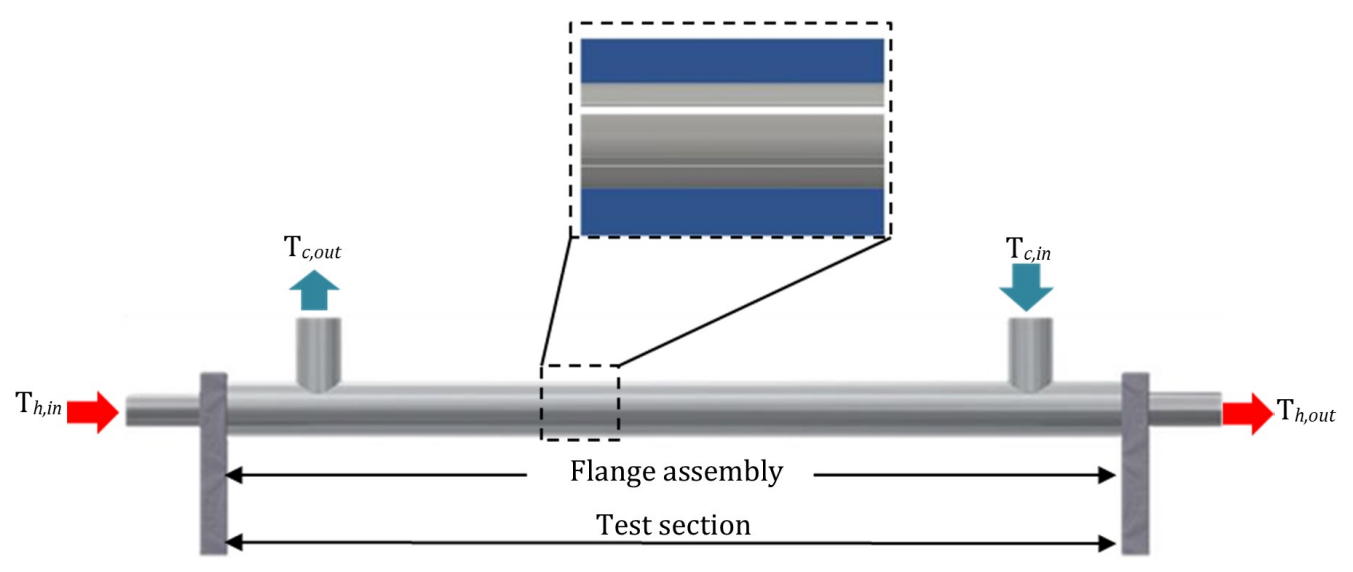

Figure 2. Test section.

test section surfaces were well insulated by a thermal insulator.

The temperature of the hot fluid was $50 \pm 0.5^{\circ} \mathrm{C}$ and that of the cold fluid was $30 \pm 0.5^{\circ} \mathrm{C}$. The cold fluid volume flowrate varied from 11 litres per minute (lpm) to 15 litres per minute (lpm) in a direct correlation to the Reynolds number (Re) between 33000 and 46000 , respectively. In addition, the Reynolds number of the hot fluid was kept constant at around 30000 .

\subsection{Specification Details of Groove}

The configuration of the geometrical features and the details of the groove are shown in Figure 3 The $50 \mathrm{~cm}$ long test section was a double pipe heat exchanger placed horizontally. The tube was made from aluminium tube with a $19.8 \mathrm{~mm}$ outer diameter. The shell was made of an acrylic tube with a $27.5 \mathrm{~mm}$ inner diameter.

The outer surface of the aluminium tube was etched using longitudinal-rectangular grooves. The grooves were created using a conventional etching technique, with a groove depth (t) of $0.3 \mathrm{~mm}$ and groove width (l) of $1 \mathrm{~mm}$. The experiment was carried out with 4 pipes, one with 2 longitudinal grooves, one with 4 longitudinal grooves, one with 6 longitudinal grooves and one with 8 longitudinal grooves. The longitudinal grooves were incised into the pipe walls using conventional techniques. In this investigation the smooth annulus was used as the control parameter.

\subsection{MeAsurement}

K-type thermocouples with $0.3 \mathrm{~mm}$ in diameter were used to measure the temperature of both the entry and 

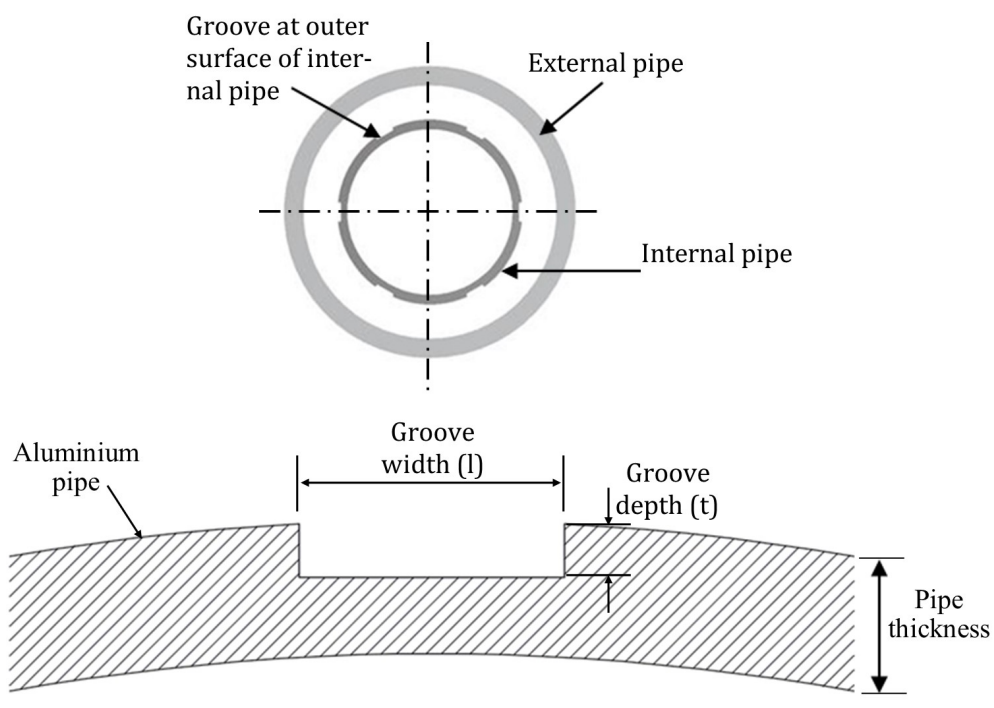

FiguRE 3. Groove cross sectional view on double pipe heat exchanger.

the exit points of the working fluid in the test section. A data logger was used to digitalize the thermocouples' signal and record for $600 \mathrm{~s}$. To measure the pressure of the cold fluid section, the pressure transducers MPX 5050 D were used at the frequency of $10 \mathrm{~Hz}$. A rotameters were used to measure the flowrate of the hot and cold fluid loops.

\subsection{DATA REDUCTION AND UNCERTAINTY ANALYSIS}

In this study, important parameters were calculated to evaluate the effect of the number of longitudinal grooves on a heat exchanger at different Reynolds numbers.

$$
Q_{h}=Q_{c}
$$

Given that the difference between $Q_{h}$ and $Q_{c}$ was less than $5 \%$, the actual heat transferred from the hot water to the cold water flowing in the annulus room was calculated from the cold fluid side using the following equation,

$$
\begin{gathered}
Q=\dot{m} \cdot C \cdot\left(\Delta T_{c}\right) \\
Q=\rho \cdot V \cdot C \cdot\left(T_{\text {cout }}-T_{\text {cin }}\right)
\end{gathered}
$$

The other indicators of the heat transfer performance were the Reynolds number (Re), friction factor $(f)$, real heat transfer $(Q)$, heat capacity ratio $(c)$, Number of transfer unit (NTU), and effectiveness $(e)$.

The Reynolds number (Re) was computed using the equation below:

$$
R e=\frac{u \cdot D_{h}}{\nu}
$$

The annulus hydraulic diameter was calculated using the equation below:

$$
D_{h}=D_{2}-D_{1}
$$

The friction factor $(f)$ inside the annulus was calculated from the value of the pressure drop using the equation below:

$$
f=\frac{2 \cdot D_{h} \cdot \Delta P}{l \cdot \rho \cdot u^{2}}
$$

The enhancement of the heat transfer process and the heat capacity ratio was estimated using the following equations:

$$
\begin{gathered}
E_{h}=\frac{Q_{\text {groove }}}{Q_{\text {smooth }}} \\
c=\frac{c_{\text {min }}}{c_{\max }}
\end{gathered}
$$

The NTU, Effectiveness, and UA values were computed using the equations below,

$$
\begin{gathered}
N T U=\frac{U \cdot A}{c_{\min }} \\
\varepsilon=\frac{1-\exp (-N T U(1-c))}{1-c \exp (-N T U(1-c))} \\
Q=U \cdot A \cdot \Delta T_{l m}
\end{gathered}
$$

\subsection{UNCERTAINTY ANALYSIS}

The accuracy level of the temperature data acquisition was about $0.4 \%$. The difference between the pressure inlet and outlet of the annulus being measured by pressure transducers had a level of accuracy of about 


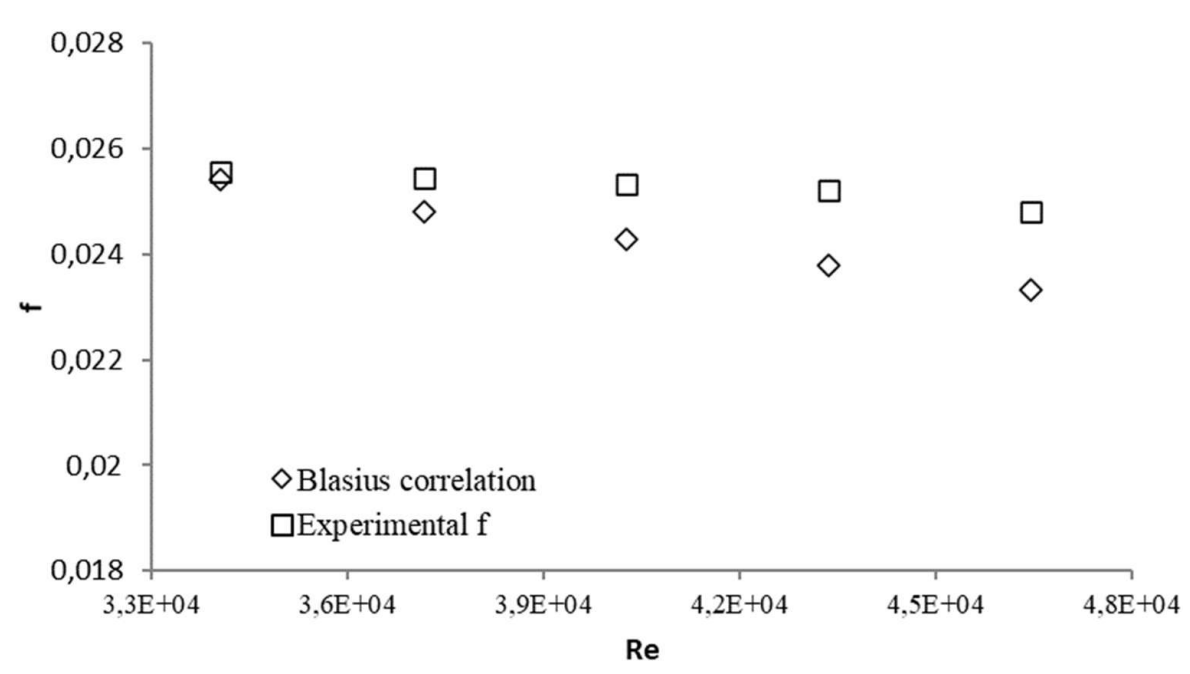

FIGURE 4. Validation test for friction of smooth pipe.

$2.5 \%$. Then, a rotameter with an accuracy level of about $5 \%$ was used to measure the working fluid volume flow rate. The uncertainty of these physical and flow parameters was calculated by the method offered by [43].

$$
u_{m}= \pm\left[\left(\frac{\Delta T}{T}\right)^{2}+\left(\frac{\Delta p}{p}\right)^{2}+\left(\frac{\Delta V}{V}\right)^{2}\right]^{1 / 2}
$$

Using equation (12), it was found that this experiment's uncertainty was less than $5 \%$.

\section{Results And Discussion}

\subsection{VALIDATION TEST OF FRICTION OF SMOOTH ANNULUS EXPERIMENTAL DATA}

Firstly, the result obtained in this experiment on the characteristics of the pressure drop in the smooth annulus was verified in terms of the friction factor using equation 6 above. To achieve the level of confidence in the experimental procedure, the friction factor value from the smooth annulus was compared to Blasius equation [4].

$$
f=0.448 \operatorname{Re}^{-0.275}
$$

The flow resistance of the smooth annulus, shown as the friction factor, is presented in Figure 4. It was found that the experimental value of the friction factor corresponded with the predicted result from the Blasius equation. The absolute deviations obtained for $f$ ranged from $1 \%$ to $6.5 \%$.

\subsection{The EFFECT OF THE NUMBER OF LONGITUDINAL GROOVES ON THE HEAT TRANSFER}

Figure 5 shows the value of the heat transfer in the annulus for various cold fluid Reynold numbers. As presented, the heat transfer rate increased as the Reynolds number of the cold water increased. This phenomenon is caused by the heat transfer process, which depends on the heat capacity of the cold fluid, through the tube surface. As Figure 5 shows, the heat transfer of the annulus with 8 grooves was higher than that of the annulus with 2 grooves, 4 grooves and 6 grooves. And it can be seen that the heat transfer that occurred in the latter three types of annuli were higher than that occurring in the annulus without any grooves. The highest increase of heat transfer occurred at the highest Re, and the observed heat transfer increase in the annulus with 8 grooves was $1.05-1.15$. Due to the resulting turbulence intensity, the intensity of the heat transferred and heat absorbed by the cold fluid in the annulus with 8 grooves was higher than in the case of other annuli.

Figure 6 shows the pattern of relationship between the overall heat transfer coefficient and Reynolds number of the cold fluid. It is evident that the trend of the $\mathrm{U}$ value was similar to the patterns of the heat transfer trend in Figure 5. In this case, the same justification described for Figure 5 can be made for Figure 6 The turbulence intensity, recirculation region and fluid momentum are the phenomena that will tear the thermal boundary layer so that the obstacle of heat transfer will be thinner. It was also found that the increase in the real heat transfer was accompanied by a similar increase in the cold-water mass flow rate indicating an overall increase in heat transfer. Looking at Figure 7 , which describes the correlation between the number of transfer unit (NTU) and effectiveness, it can be seen that the number of grooves affected the NTU and effectiveness. The increase in the heat transfer and the $U$ value was the product of increasing the number of grooves, from the smooth pipe to 2 grooves, 4 grooves, 6 grooves and 8 grooves. 


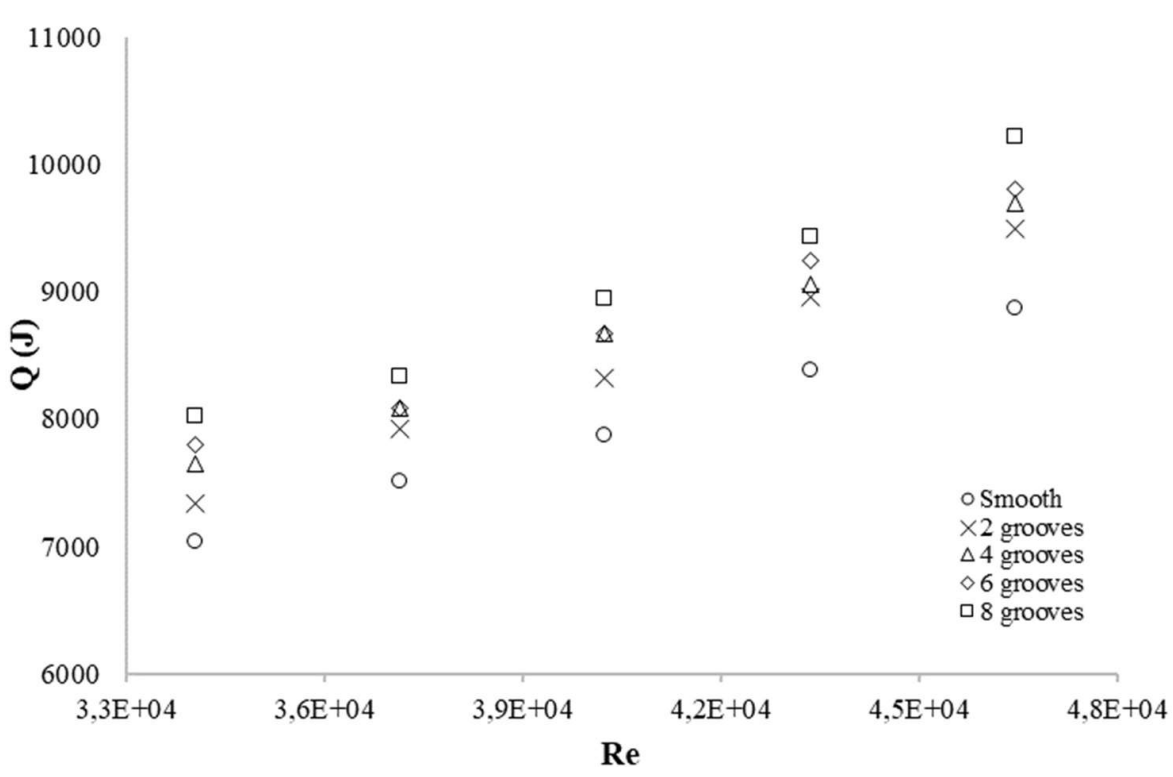

FiguRE 5. Real heat transfers with various Re for different numbers of grooves.

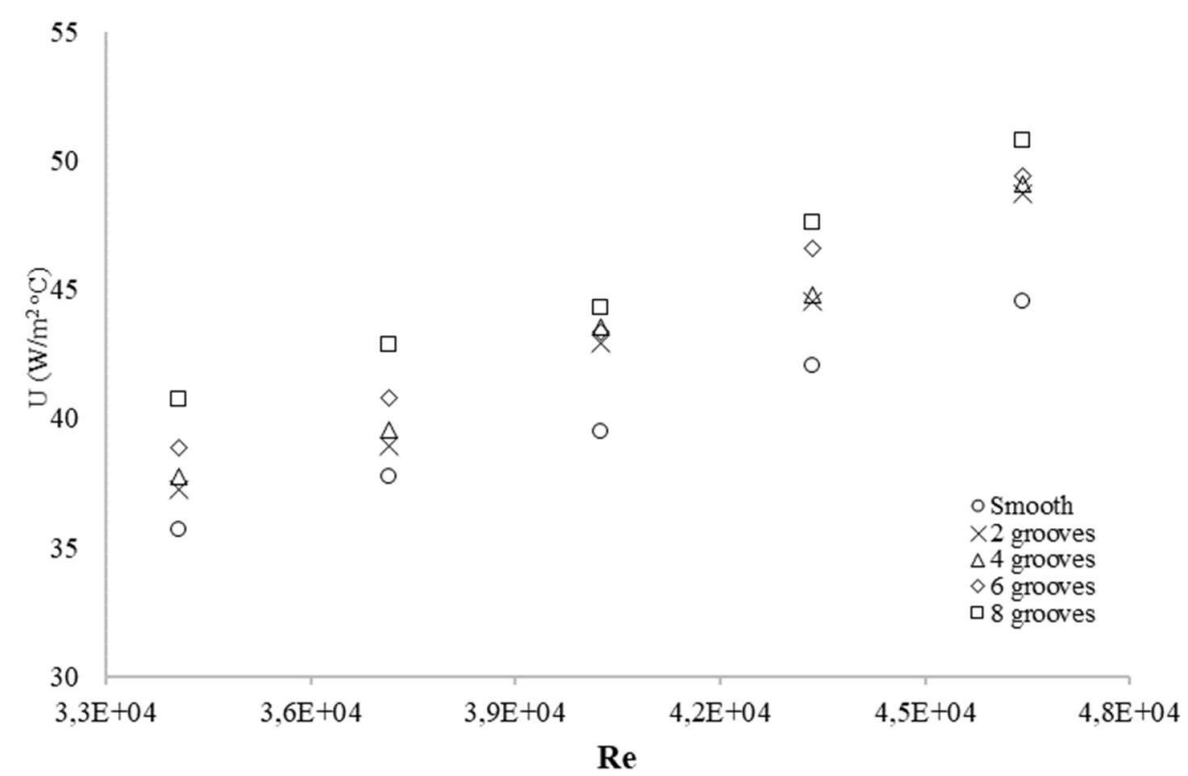

FiguRE 6. Overall heat transfer coefficient on various Reynold number.

\subsection{Comparison OF THE EFFECTIVEnESS AND NTU OBTAINED FROM THE SMOOTH PIPE AND THAT OF GROOVED PIPES ON THE ENHANCEMENT OF HEAT TRANSFER}

Figure 7 shows the relationship between the NTU and effectiveness obtained from the smooth pipe and the longitudinally-grooved pipe. Numbers 1 through 5 denote the heat capacity ratio at a specified Reynolds number in this experiment. It is obvious from Figure 7 that at a specified heat capacity ratio, the correlation point between the NTU and effectiveness from the grooved pipe was located more towards the right side as compared with that obtained from the smooth annulus. The point getting towards the right side and higher up in Figure 7 indicates an increase in the effectiveness and NTU.
The actual increase in the heat transfer was indicated by the increase in the effectiveness value. The increase in the NTU value represents the increase in the (UA) value of the annulus system. Looking at Figure 7 it is clear that the correlation between the effectiveness and NTU of the grooved annulus, indicated by the dot and dash line, was almost similar to the result obtained by 45 . Increasing the number of longitudinal grooves in the annulus led to the increase in the NTU and effectiveness. Figure 7 also shows that the annulus having eight grooves had the highest NTU and effectiveness. The swirl flow generated in the groove valley was increased by increasing the number of grooves. This secondary flow was responsible for weakening the thermal boundary layer. 


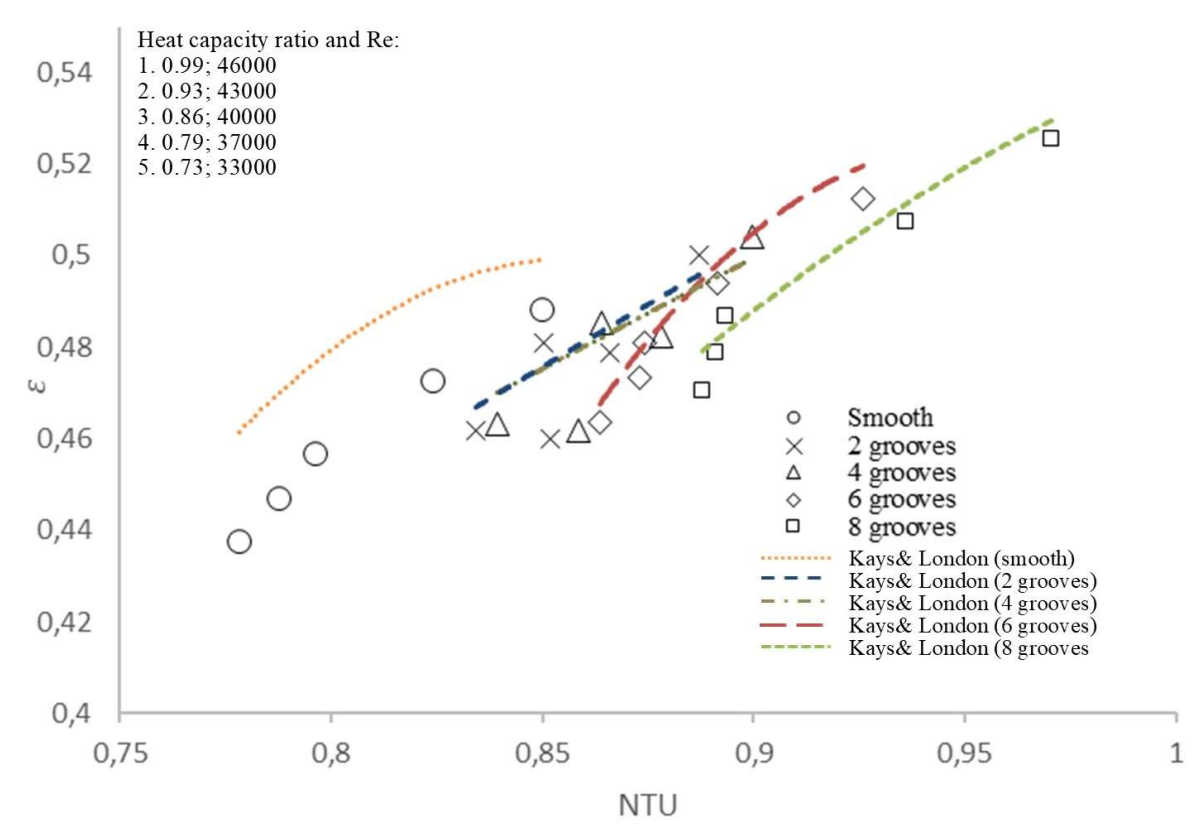

FiguRE 7. Relationship of NTU and effectiveness for different numbers of grooves.

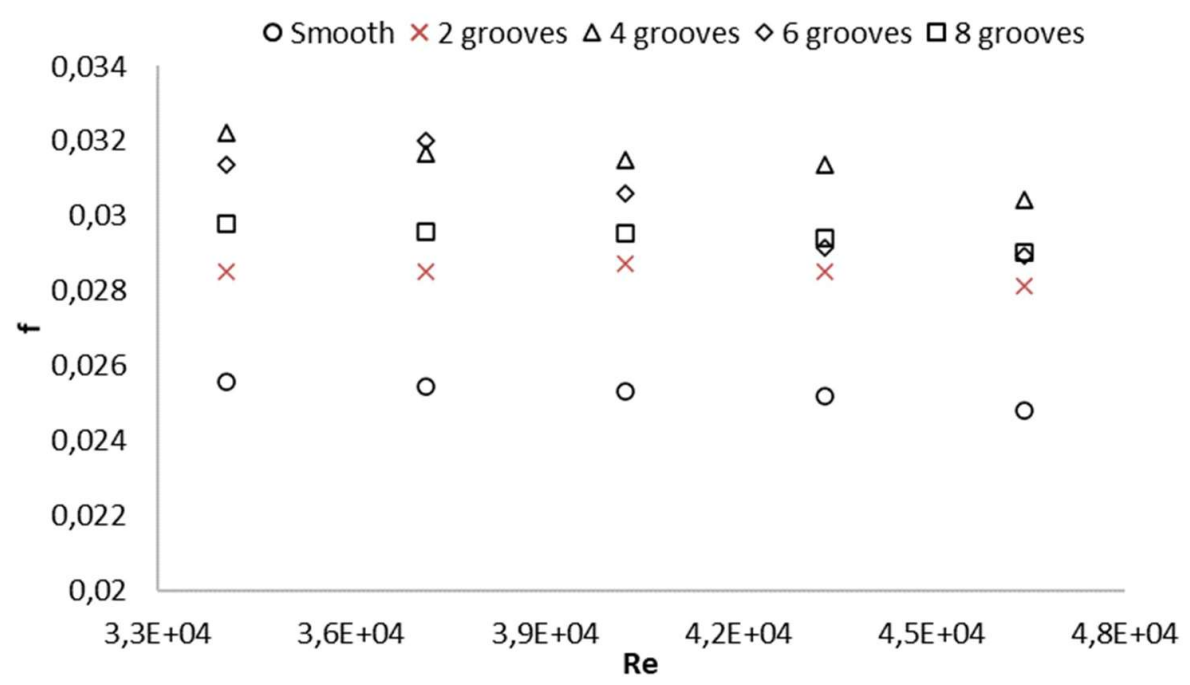

FIGURE 8. Friction factor and Reynolds number correlation for various numbers of grooves.

\subsection{COMPARISON OF THE FRICTION FACTOR OF SMOOTH ANNULUS AND GROOVED ANNULI}

Figure 8 indicates the assessment of the friction produced in the smooth annulus and the annulus with different numbers of grooves. It was evident that the friction slightly decreased with the increase of Reynolds number of the cold water in the smooth annulus, and a similar decrease also occurred in the grooved annulus with the Reynolds number being constant. The flow characteristics of the grooved annulus was more complex in the grooved annuli as compared with those occurring in the smooth annulus. The friction factor was generated by swirls and augmented turbulence on the surface of the annulus and in the groove valley area. This phenomenon increased the velocity gradient inside the groove, sheared stress on the surface of the tube and the recirculation region.
Moreover, it also increased the pressure drop and the friction factor of the grooved annulus.

As expected, the friction obtained from all cases in the grooved annulus was significantly higher than those obtained in the annulus with no grooves. The value of the friction factor was affected by the formation and interaction of large-scale and small-scale fluid motion. The increase in the energetic smallscale fluid motion increased the velocity gradient and shear stress at the tube surface and inside the groove valley. It is well identified that the square of the velocity is proportional to the pressure drop. Figure 8 also reveals that the annulus having four grooves had the highest friction factor as compared to the others. Meanwhile, the annulus with eight grooves had a moderate friction and had the lowest thermal resistance. It is indicated by the value of the heat transfer inside the heat exchanger shown in Figures 5, 6, and 7 


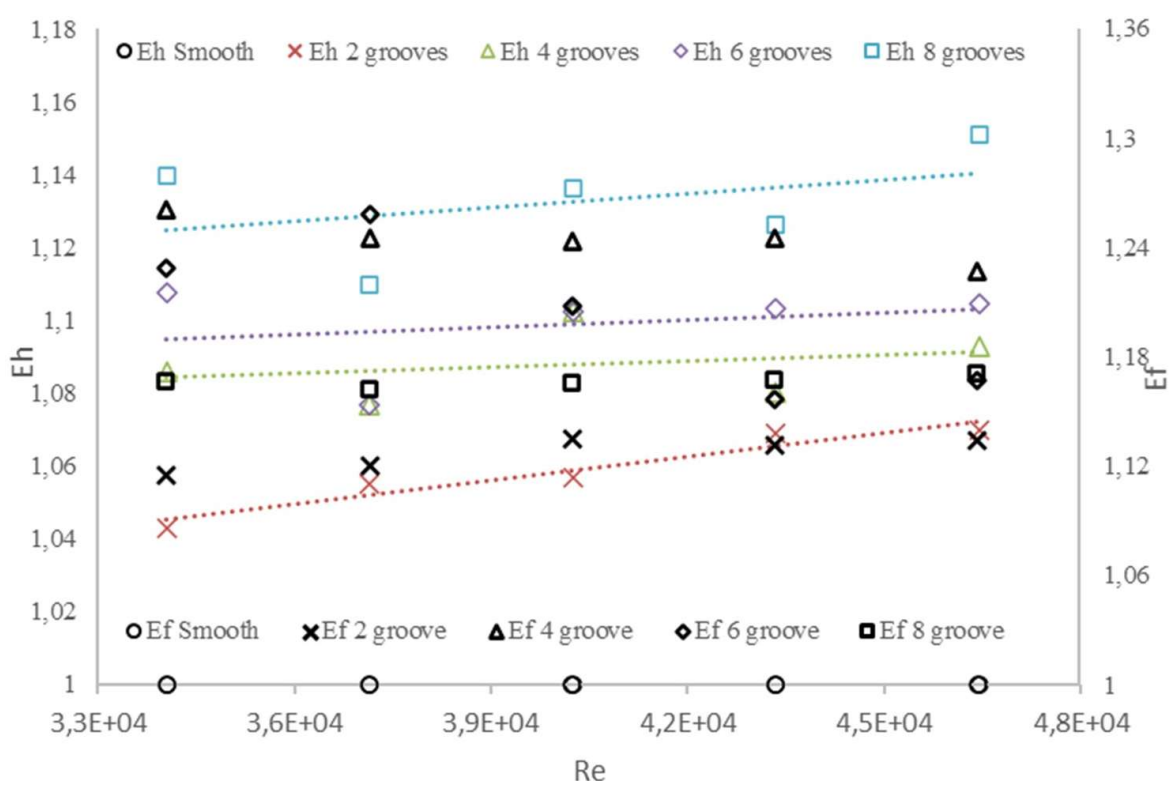

FiguRE 9. Heat transfer enhancement, friction factor enhancement and Reynolds number correlation for various number of grooves.

\subsection{COMPENSATION OF HeAT TRANSFER AND FRICTION}

Let us now turn to the heat transfer performance and the compensation for the friction occurring in the grooved annulus tubes compared with the annulus with no grooves. Figure 9 shows the compensation for the heat transfer and friction. The analysis conducted under the constraints of an identical Re showed that the heat transfer performance of the annulus with eight grooves increased by up to $15 \%$ and was much better than that of the annulus without any grooves and others with fewer numbers of grooves.

Meanwhile, the friction performance of the annulus with four grooves increased by up to $27 \%$ and was much higher than that of the annulus without any grooves and the others with fewer numbers of grooves. The point of the heat transfer enhancement should have a higher position relative to the point of the friction enhancement to be considered a good agreement of compensation. The increase in the gap between these two parameters should constitute the indicator of increasing the overall grooved system performance. In the present study, the annulus with eight grooves was the best candidate for the compensation for the heat transfer and friction.

\section{Conclusions}

This study examined how a heat transfer enhancement and friction occurred in a double pipe heat exchanger with longitudinal grooves. The effects of the number of longitudinal grooves in an annulus, the cold-water flow rate and the friction factor were measured. The swirl flow and turbulence augmentation occurring near the annulus' surface and inside the groove valley caused the convective heat transfer within the grooved annulus to be higher than that of the smooth annulus.
The study found that the annulus with eight grooves produced good results (compared with the smooth annulus) with a better compensation between the heat transfer, which increased by about $15 \%$, and the friction, which increased by about $16 \%$. This study showed that incising the longitudinal-grooved structure on an annulus of a heat exchanger influenced the flow on the pipe surface leading to the increase in the heat transfer enhancement and the friction factor as well.

\section{ACKNOWLEDGEMENTS}

The authors would like to express their gratitude to the DRPM Ristek Dikti-Indonesian Government by No. 833/PL8/LT/2019 for providing a financial support. Also the Bali State Polytechnic for all the administrative support.

\section{LIST OF SYMBOLS}

$A$ surface area $\left[\mathrm{m}^{2}\right]$

$c$ heat capacity ratio

$C_{\text {min }}$ the smallest heat capacity rate $\left[\mathrm{W} /{ }^{\circ} \mathrm{C}\right]$

$C_{\max }$ the highest heat capacity rate $\left[\mathrm{W} /{ }^{\circ} \mathrm{C}\right]$

$D_{h}$ hydraulic diameter $[\mathrm{m}]$

$D_{1}$ outlet diameter of tube side $[\mathrm{m}]$

$D_{2}$ inner diameter of shell side $[\mathrm{m}]$

$\varepsilon$ effectiveness

$E_{h}$ heat transfer enhancement

$E_{f}$ friction enhancement

$f$ friction factor

$l$ pipe long $[\mathrm{m}]$

$\dot{m}$ mass flow rate $[\mathrm{kg} / \mathrm{s}]$

$N T U$ number of transfer unit

$\mathrm{Pa}$ pressure [p]

$Q$ heat transfer $[\mathrm{J}]$

Re Reynolds number 
$T$ temperature $\left[{ }^{\circ} \mathrm{C}\right]$

$u$ velocity $[\mathrm{m} / \mathrm{s}]$

$U$ overall heat transfer coefficient $\left[\mathrm{W} / \mathrm{m}^{2}{ }^{\circ} \mathrm{C}\right]$

$u_{m}$ uncertainty

$\nu \quad$ kinematic viscosity $\left[\mathrm{m}^{2} / \mathrm{s}\right]$

$V$ volumetric flow rate $\left[\mathrm{m}^{3} / \mathrm{s}\right]$

$\Delta p$ pressure drop $[\mathrm{Pa}]$

$\Delta T$ fluid temperature difference in time period $\left[{ }^{\circ} \mathrm{Cs}\right]$

$\Delta V$ volumetric flow rate difference $\left[\mathrm{m}^{3} / \mathrm{s}\right]$

$\rho$ density $\left[\mathrm{kg} / \mathrm{m}^{3}\right]$

\section{Subscripts}

$c$ cold fluid

$h$ hot fluid

in inlet

lm LMTD

out outlet

\section{REFERENCES}

[1] Y. Cao, H. Ke, Y. Lin, et al. Investigation on the flow noise propagation mechanism in pipelines of shell-andtube heat exchangers based on synergy principle of flow and sound fields. Applied Thermal Engineering 122:339 - 349, 2017. DOI:10.1016/j.applthermaleng.2017.04.057

[2] H. Akhavan-Zanjani, M. Saffar-Avval,

M. Mansourkiaei, et al. Experimental investigation of laminar forced convective heat transfer of Graphene-water nanofluid inside a circular tube. International Journal of Thermal Sciences 100:316 323, 2016. DOI:10.1016/j.ijthermalsci.2015.10.003

[3] J. Opatřil, J. Havlík, O. Bartoš, T. Douhý. An experimental assessment of the plate heat exchanger characteristics by Wilson plot method. Acta Polytechnica 56(5):367 - 372, 2016. DOI:10.14311/AP.2016.56.0367.

[4] D. Ndiaye. Transient model of a refrigerant-to-water helically coiled tube-in-tube heat exchanger with corrugated inner tube. Applied Thermal Engineering 112:413 - 423, 2017. DOI:10.1016/j.applthermaleng.2016.10.045.

[5] L. Yang, H. Han, Y. Li, X. Li. A numerical study of the flow and heat transfer characteristics of outward convex corrugated tubes with twisted-tape insert. Journal of Heat Transfer 138(2):024501, 2016.

[6] Y. Hong, J. Du, S. Wang. Experimental heat transfer and flow characteristics in a spiral grooved tube with overlapped large/small twin twisted tapes. International Journal of Heat and Mass Transfer 106:1178 1190, 2016. DOI:10.1016/j.ijheatmasstransfer.2016.10.098

[7] N. Piriyarungrod, M. Kumar, C. Thianpong, et al. Intensification of thermo-hydraulic performance in heat exchanger tube inserted with multiple twisted-tapes. Applied Thermal Engineering 136:516 - 530, 2018. DOI:10.1016/j.applthermaleng.2018.02.097.

[8] S. Eiamsa-Ard, P. Promvonge. Thermal characteristics of turbulent rib-grooved channel flows. International Communications in Heat and Mass Transfer 36(7):705 711, 2009. DOI:10.1016/j.icheatmasstransfer.2009.03.025.

[9] P. Sunu, M. Rasta. Heat transfer enhancement and pressure drop of grooved annulus of double pipe heat exchanger. Acta Polytechnica 57(2):125 - 130, 2017. DOI:10.14311/AP.2017.57.0125.
[10] P. W. Sunu, I. N. G. Wardana, A. A. Sonief, N. Hamidi. The effect of wall groove numbers on pressure drop in pipe flows. International Journal of Fluid Mechanics Research 42(2):119 - 130, 2015. DOI:10.1615/InterJFluidMechRes.v42.i2.30.

[11] K. Aroonrat, C. Jumpholkul, R. Leelaprachakul, et al. Heat transfer and single-phase flow in internally grooved tubes. International Communications in Heat and Mass Transfer 42:62 - 68, 2013. DOI:10.1016/j.icheatmasstransfer.2012.12.001.

[12] S. Huang. VIV suppression of a two-degree-offreedom circular cylinder and drag reduction of a fixed circular cylinder by the use of helical grooves. Journal of Fluids and Structures 27(7):1124 - 1133, 2011. DOI:10.1016/j.jfluidstructs.2011.07.005

[13] S. Eiamsa-Ard, P. Promvonge. Numerical study on heat transfer of turbulent channel flow over periodic grooves. International Communications in Heat and Mass Transfer 35(7):844 - 852, 2008. DOI:10.1016/j.icheatmasstransfer.2008.03.008.

[14] P. Sunu, I. Wardana, A. Sonief, N. Hamidi. Flow behavior and friction factor in internally grooved pipe wall. Advanced Studies in Theoretical Physics 8(14):643 - 647, 2014. DOI:10.12988/astp.2014.4573

[15] P. Sunu. The characteristics of increased pressure drop in pipes with grooved. Advanced Studies in Theoretical Physics 9(2):57 - 61, 2015. DOI:10.12988/astp.2015.412152

[16] T. Adachi, Y. Tashiro, H. Arima, Y. Ikegami. Pressure drop characteristics of flow in a symmetric channel with periodically expanded grooves. Chemical Engineering Science 64(3):593 - 597, 2009. DOI:10.1016/j.ces.2008.10.041

[17] Sutardi, C. Ching. Effect of a transverse square groove on a turbulent boundary layer. Experimental Thermal and Fluid Science 20(1):1 - 10, 1999. DOI:10.1016/S0894-1777(99)00031-X

[18] S. Rainieri, G. Pagliarini (22):4525 - 4536, 2002.

[19] C. ua Qi, X. Han, H. qing Lv, et al. Experimental study of heat transfer and scale formation of spiral grooved tube in the falling film distilled desalination. International Journal of Heat and Mass Transfer 119:654-664, 2018 DOI:10.1016/j.ijheatmasstransfer.2017.11.148

[20] Y. Chen, J. Tian, Y. Fu, et al. Experimental study of heat transfer enhancement for molten salt with transversely grooved tube heat exchanger in laminar-transition-turbulent regimes. Applied Thermal Engineering 132:95 - 101, 2018. DOI:10.1016/j.applthermaleng.2017.12.054

[21] J. Pan, Y. Bian, Y. Liu, et al. Characteristics of flow behavior and heat transfer in the grooved channel for pulsatile flow with a reverse flow. International Journal of Heat and Mass Transfer 147:118932, 2020. DOI:10.1016/j.ijheatmasstransfer.2019.118932.

[22] A. A. R. Darzi, M. Farhadi, K. Sedighi. Experimental investigation of convective heat transfer and friction factor of $\mathrm{Al}_{2} \mathrm{O}_{3} /$ water nanofluid in helically corrugated tube. Experimental Thermal and Fluid Science 57:188199, 2014. DOI:10.1016/j.expthermflusci.2014.04.024 
[23] P. Kathait, A. Patil. Thermo-hydraulic performance of a heat exchanger tube with discrete corrugations. Applied Thermal Engineering 66(1 - 2):162 - 170, 2014. DOI:10.1016/j.applthermaleng.2014.01.069

[24] S. Lorenz, D. Mukomilow, W. Leiner. Distribution of the heat transfer coefficient in a channel with periodic transverse grooves. Experimental Thermal and Fluid Science 11(3):234 - 242, 1995. DOI:10.1016/0894-1777(95)00055-Q

[25] T. Adachi, H. Uehara. Correlation between heat transfer and pressure drop in channels with periodically grooved parts. International Journal of Heat and Mass Transfer 44(22):4333 - 4343, 2001. DOI:10.1016/S0017-9310(01)00070-9

[26] M. Jain, A. Rao, K. Nandakumar. Numerical study on shape optimization of groove micromixers.

Microfluidics and Nanofluidics 15(5):689 - 699, 2013. DOI:10.1007/s10404-013-1169-x

[27] C. Wang, Z. Liu, G. Zhang, M. Zhang. Experimental investigations of flat plate heat pipes with interlaced narrow grooves or channels as capillary structure. Experimental Thermal and Fluid Science 48:222 - 229, 2013. DOI:10.1016/j.expthermflusci.2013.03.004

[28] Sunu, Putu Wijaya, Anakottapary, Daud Simon, Santika, Wayan G. Temperature approach optimization in the double pipe heat exchanger with groove. In The 3rd Bali International Seminar on Science $\mathbb{E}$ Technology (BISSTECH 2015), vol. 58, p. 04006. 2016. DOI:10.1051/matecconf/20165804006.

[29] M. C. Vlachou, C. Efstathiou, A. Antoniadis, T. D. Karapantsios. Micro-grooved surfaces to enhance flow boiling in a macro-channel. Experimental Thermal and Fluid Science 108:61 - 74, 2019. DOI:10.1016/j.expthermflusci.2019.05.015

[30] A. Mehri, P. Akbarzadeh. Hydrodynamic characteristics of heated/non-heated and grooved/un-grooved spheres during free-surface water entry. Journal of Fluids and Structures 97:103100, 2020. DOI:10.1016/j.jfluidstructs.2020.103100

[31] P. Promvonge, P. Tongyote, S. Skullong. Thermal behaviors in heat exchanger channel with V-shaped ribs and grooves. Chemical Engineering Research and Design 150:263 - 273, 2019. DOI:10.1016/j.cherd.2019.07.025

[32] R. Naveenkumar, N. Karthikeyan, S. Gopan, et al. Analysis of heat transfer in grooved plain carbon steel tube for solar applications. In International Conference on Nanotechnology: Ideas, Innovation and Industries, Materials Today: Proceedings, Part 7, vol. 33, pp. 4219 4223. 2020. DOI:10.1016/j.matpr.2020.07.234

[33] S. K. Saha. Thermohydraulics of laminar flow of viscous oil through a circular tube having axial corrugations and fitted with centre-cleared twisted-tape. Experimental Thermal and Fluid Science 38:201 - 209, 2012. DOI:10.1016/j.expthermflusci.2011.12.008
[34] S. K. Saha, B. Swain, G. L. Dayanidhi. Friction and thermal characteristics of laminar flow of viscous oil through a circular tube having axial corrugations and fitted with helical screw-tape inserts. Journal of Fluids Engineering, Transactions of the ASME 134(5):051210, 2012. DOI:10.1115/1.4006669

[35] S. K. Saha. Thermohydraulics of turbulent flow through rectangular and square ducts with axial corrugation roughness and twisted-tapes with and without oblique teeth. Experimental Thermal and Fluid Science 34(6):744 - 752, 2010. DOI:10.1016/j.expthermflusci.2010.01.003

[36] A. R. Anand. Analytical and experimental investigations on heat transport capability of axially grooved aluminium-methane heat pipe. International Journal of Thermal Sciences 139:269 - 281, 2019. DOI:10.1016/j.ijthermalsci.2019.01.028.

[37] A. R. Anand. Investigations on effect of evaporator length on heat transport of axially grooved ammonia heat pipe. Applied Thermal Engineering 150:1233 1242, 2019. DOI:10.1016/j.applthermaleng.2019.01.078

[38] A. Bahmanabadi, M. Faegh, M. B. Shafii. Experimental examination of utilizing novel radially grooved surfaces in the evaporator of a thermosyphon heat pipe. Applied Thermal Engineering 169:114975, 2020. DOI:10.1016/j.applthermaleng.2020.114975.

[39] B. Zhou, X. Wang, W. Guo, et al. Experimental measurements of the drag force and the near-wake flow patterns of a longitudinally grooved cylinder. Journal of Wind Engineering and Industrial Aerodynamics 145:30 - 41, 2015. DOI:10.1016/j.jweia.2015.05.013

[40] N. Fujisawa, K. Hirabayashi, T. Yamagata. Aerodynamic noise reduction of circular cylinder by longitudinal grooves. Journal of Wind Engineering and Industrial Aerodynamics 199:104129, 2020. DOI:10.1016/j.jweia.2020.104129

[41] J. Han, Y. Zhang, W. Wang, et al. Effect of grooves on the double-nosed projectile penetrating into plain concrete target. International Journal of Impact Engineering 140:103544, 2020. DOI:10.1016/j.ijimpeng.2020.103544

[42] S. W. Gepner, N. Yadav, J. Szumbarski. Secondary flows in a longitudinally grooved channel and enhancement of diffusive transport. International Journal of Heat and Mass Transfer 153:119523, 2020. DOI:10.1016/j.ijheatmasstransfer.2020.119523

[43] R. J. Moffat. Describing the uncertainties in experimental results. Experimental Thermal and Fluid Science 1(1):3 - 17, 1988. DOI:10.1016/0894-1777(88)90043-X

[44] M. N. Ozisik. Heat Transfer: A Basic Approach. McGraw-Hill International Editions, New York, 1985.

[45] W. M. Kays, A. L. London. Compact Heat Exchanger. McGraw-Hill International Editions, New York, 3rd edn., 1984. 